\title{
Zinc Oxide Nanoparticles Catalyzed Condensation Reaction of Isocoumarins and 1,7-Heptadiamine in the Formation of Bis-Isoquinolinones
}

\author{
Varadhan Krishnakumar, ${ }^{1,2}$ Kesarla Mohan Kumar, ${ }^{2}$ Badal Kumar Mandal, ${ }^{2}$ \\ and Fazlur-Rahman Nawaz Khan ${ }^{1}$ \\ ${ }^{1}$ Organic Chemistry Division, School of Advanced Sciences, VIT University, Tamil Nadu, Vellore 632 014, India \\ ${ }^{2}$ Trace Elements Speciation Research Laboratory, Environmental and Analytical Chemistry Division, School of Advanced Sciences, \\ VIT University, Tamil Nadu, Vellore 632 014, India
}

Correspondence should be addressed to Badal Kumar Mandal, badalmandal@vit.ac.in and

Fazlur-Rahman Nawaz Khan, nawaz_f@yahoo.co.in

Received 31 October 2011; Accepted 30 November 2011

Academic Editors: N. T. Patil and I. Shibata

Copyright ( 92012 Varadhan Krishnakumar et al. This is an open access article distributed under the Creative Commons Attribution License, which permits unrestricted use, distribution, and reproduction in any medium, provided the original work is properly cited.

\begin{abstract}
The diversified bis-isoquinolinones were obtained in two steps, utilizing homophthalic acid and various acid chlorides providing 3 -substituted isocoumarins in the first step which on further condensation with 1,7-heptadiamine involving C-N bond formation from the lactone in the presence of $10 \mathrm{~mol} \%$ zinc oxide nanoparticles (ZnO NPs) $(<150 \mathrm{~nm})$ afforded the desired bisisoquinolinones in high yield and purity. The synthesized compounds were then characterized using FTIR, ${ }^{1} \mathrm{H}$ NMR, ${ }^{13} \mathrm{C}$ NMR, and HRMS techniques.
\end{abstract}

\section{Introduction}

The isoquinolinones form the core structures of plant alkaloids [1] and biologically important compounds [2-5]. In recent decades, isoquinolinones have been used as a precursor of phenylisoquinoline-iridium complex, a high-efficiency red phosphorescent dopant, in organic light-emitting diodes (OLEDs) $[6,7]$. There are many reports for their synthesis including cyclization of 2-chlorobenzonitriles and keto esters [8], condensation of 2-(bromomethyl)benzonitriles [9], 2-methylbenzonitrile and 2-methylbenzamide [10], 2halobenzaldimines and alkynes [11], denitrogenative addition of benzotriazinones and alkynes [12], double metalation of arylbenzamides [13,14], N-pyridinylphthalimide and alkynes [15], and the metal-mediated synthesis of isoquinolinones has also been successfully emerged [16-18]. In our group, we have already reported the various 3-substituted isoquinolinones from isocoumarins $[19,20]$. Most of the above methods have limitations such as long reaction time, low yield, tedious workup procedure, and use of expensive, toxic reagents or catalysts. Indeed, methods involving C$\mathrm{O}$ bond cleavage with subsequent $\mathrm{C}-\mathrm{N}$ bond formation are emerging as attractive alternatives for isoquinolinones and that nanosized particles are considered to be attractive as catalysts for their greater reactivity, due to high surface area, recovered easily from the reaction mixture and reutilized for further reaction, therefore the method being more economical [21]. The development of efficient methods for their synthesis is of great importance, and we describe an efficient $\mathrm{ZnO}$ NPs mediated reaction for the production of bis-isoquinolinones.

\section{Experimental}

2.1. Materials and Methods. The chemicals and reagents used were purchased from Sigma Aldrich (India) and were used as purchased. Melting points were measured using open capillary tubes and are corrected with reference to benzoic acid. IR spectra (in $\mathrm{KBr}$ pellets) were recorded 


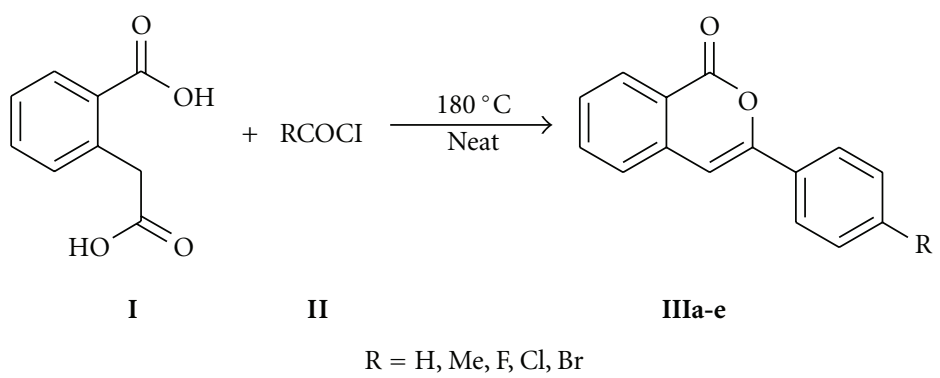

Scheme 1: Synthesis of 3-substituted isocoumarins IIIa-e.

on Nucon Infrared spectrophotometer (India). ${ }^{1} \mathrm{H}$ NMR $(400 \mathrm{MHz}$ and $500 \mathrm{MHz})$ and ${ }^{13} \mathrm{C} \mathrm{NMR}(100 \mathrm{MHz}$ and $125 \mathrm{MHz}$ ) spectra were recorded on a Bruker $400 \mathrm{MHz}$ and $500 \mathrm{MHz}$ spectrometer in $\mathrm{CDCl}_{3}$ using TMS as a standard. High-resolution mass spectra (HRMS) were obtained using JEOL GC MATE II HRMS (EI) mass spectrometry. The isocoumarins (III) required for the study were obtained following our earlier report [22] from the homophthalic acid (I) and corresponding acid chlorides (II) (Scheme 1).

2.2. Synthesis of $\mathrm{ZnO}$ Nanoparticles. The $\mathrm{ZnO} N$ ss required for the present investigation were obtained from hydrolysis of zinc acetate using sodium hydroxide as per Hu et al.'s methodology [23] with minor modification as follows. Zinc acetate dihydrate $2.2 \mathrm{~g}$ was dissolved in $300 \mathrm{~mL}$ of milli-Q water. $\mathrm{NaOH} 8 \mathrm{~g}$ was dissolved in $50 \mathrm{~mL}$ of milli-Q water. Then later solution was added dropwise into zinc acetate solution using a peristaltic pump (Revotek, India) and stirred vigorously using a magnetic stirrer for half an hour. The resulting turbid solution was placed on a temperaturecontrolled water bath at $90^{\circ} \mathrm{C}$ for one hour, and thus formed white powder was separated, washed with milli-Q water $(25 \mathrm{~mL} \times 2)$ and with ethanol $(25 \mathrm{~mL} \times 2)$, and then subjected to calcination at $300^{\circ} \mathrm{C}$ for $4 \mathrm{~h}$.

2.3. Characterization of $\mathrm{ZnO}$ Nanoparticles. The $\mathrm{ZnO}$ NPs prepared were characterized using powder X-ray diffraction (XRD), transmission electron microscope (TEM), and energy dispersive X-ray spectroscopy (EDX). The XRD was performed using Bruker D8 Advance diffractometer with $\mathrm{Cu} \mathrm{K} \alpha$ radiation $(\lambda=1.54 \AA)$. TEM images were taken (Philips TEM, Netherlands) by dropping a drop of sample dispersion $(1 \mathrm{~mL}$ samples added to $5 \mathrm{~mL}$ of propanol and sonicated for few minutes) on a carbon-coated copper grid and dried in vacuum. The instrument was operated with an acceleration voltage of $100 \mathrm{Kv}$. Simultaneously EDX spectrum was recorded at selected areas on the solid surface to obtain the information on surface atomic distribution. Average particle size and size distribution were determined according to CPS Disc Centrifuge particle size analyzer.

\subsection{General Procedure for the Synthesis of Bis-Isoquinolinone Derivatives (Va-e)}

2.4.1. Method A. The condensation of 3-substituted isocoumarins (IIIa-e) and 1,7-heptadiamine (IV) was carried out in $100 \mathrm{~mL}$ round-bottom flask fitted with Dean-Stark trap for water removal and a reflux condenser. The reaction was performed by refluxing $1 \mathrm{mmol}$ of 3 -substituted isocoumarins (III) $0.5 \mathrm{mmol}$ of 1,7-heptadiamine (IV) in the presence of catalytic amount of paratoluene sulphonic acid (pTSA) and $20 \mathrm{~mL}$ of dry toluene as a solvent. The progress of the reaction was monitored by thin layer chromatography. After completion of the reaction, the solvent was removed under vacuum, the crude product $(\mathbf{V})$ was dissolved in $20 \mathrm{~mL}$ of ethyl acetate and washed with water, then the organic layer was passed through anhydrous sodium sulphate, concentrated the solvent, and then it was purified by silica gel column chromatography using ethyl acetate and petroleum ether $(15: 85)$ mixture as an eluant.

2.4.2. Method B. A mixture of 3-substituted isocoumarins (IIIa-e) and 1,7-heptadiamine (IV) (1:0.5 ratio) in dry toluene in the presence of $10 \mathrm{~mol} \% \mathrm{ZnO}$ NPs was heated under reflux condition. The progress of the reaction was monitored by thin layer chromatography. After completion of the reaction, the catalyst was separated by filtration. The solvent was removed under vacuum, and then the crude product $(\mathbf{V})$ was purified by silica gel column chromatography using ethyl acetate and petroleum ether $(15: 85)$ mixture as an eluant. The purified products (Va-e) were characterized by FTIR, ${ }^{1} \mathrm{H}$ NMR, ${ }^{13} \mathrm{C}$ NMR, and HRMS techniques. The spectral data of compounds (Va-e) are given in Table 4.

\section{Results and Discussion}

Presently the $\mathrm{ZnO}$ NPs required for the investigation were obtained in high purity and yield from the corresponding zinc acetate solution. The XRD pattern of ZnO NPs suggested discrete diffraction peaks at 31.90, 34.40, 36.37, 47.67, 56.71, $62.98,66.51,68.05$, and 69.21 which can be assigned to (110), (002), (101), (102), (110), (103), (200), (112), and (120) of hexagonal ZnO NPs (Figure 1) and that the lattice constants were in agreement with the standard card (JCPDS no. 000361451). The TEM image of $\mathrm{ZnO} N \mathrm{NPs}$ revealed the average particle size of less than $150 \mathrm{~nm}$ (Figure 2) and further supported by particle size analysis (Figure 3 ). The EDX spectrum of the nanosample also confirmed the presence of $\mathrm{Zn}$ and $\mathrm{O}$ atoms (Figure 4).

The 3-substituted isocoumarins required for the investigation were obtained following our earlier report [22]. And preliminarily, the bis-isoquinolinones $\mathbf{V}$ were obtained from 


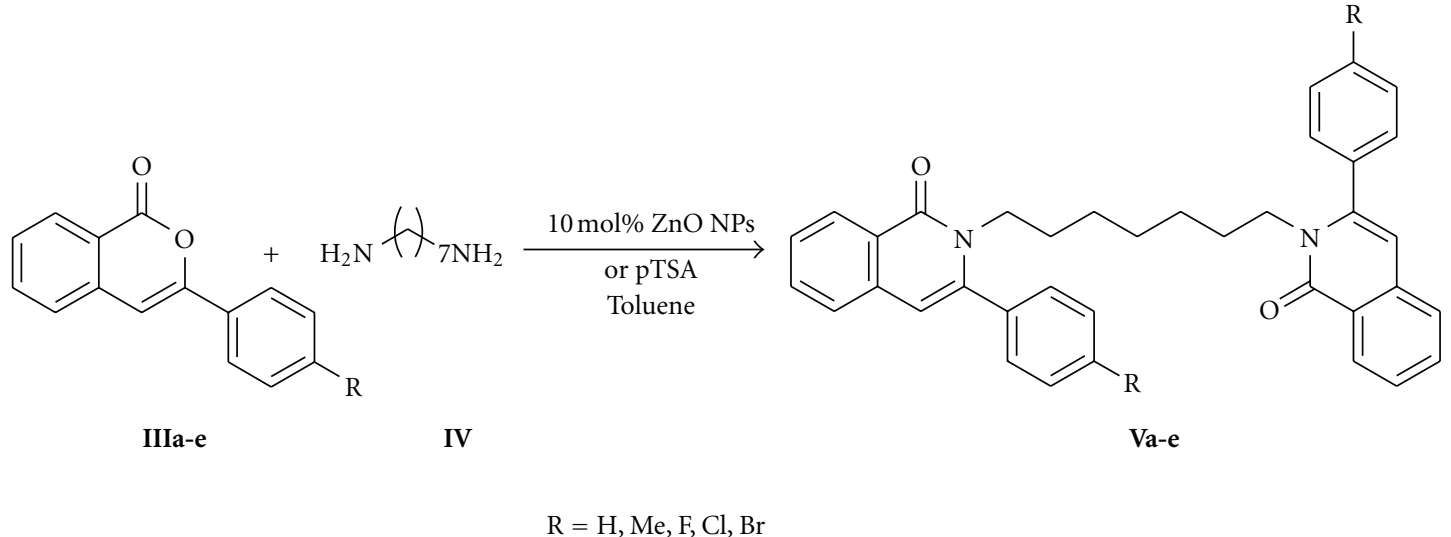

Scheme 2: Synthesis substituted bis-isoquinolinones Va-e.

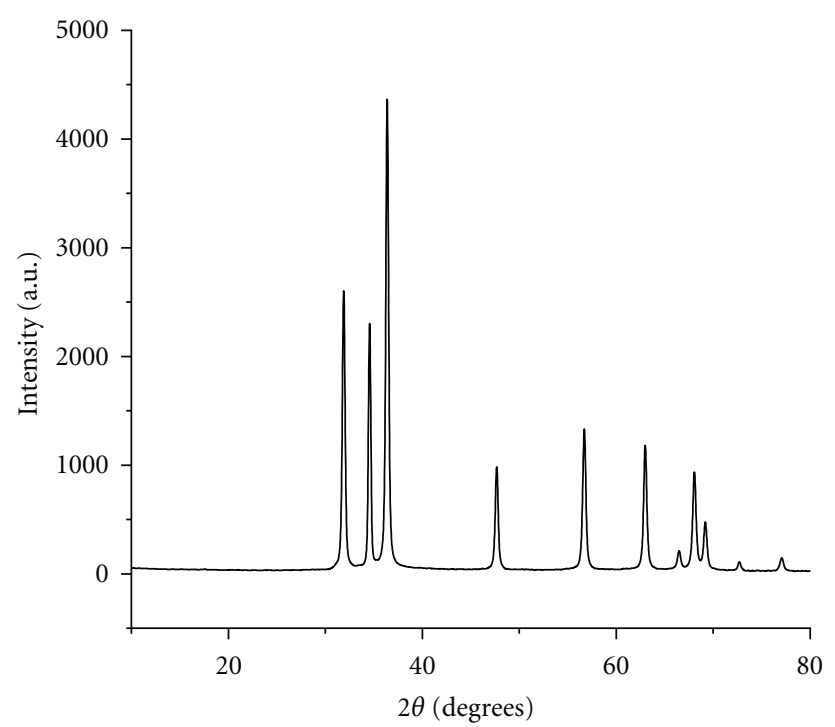

FIGURE 1: XRD pattern of ZnO NPs.

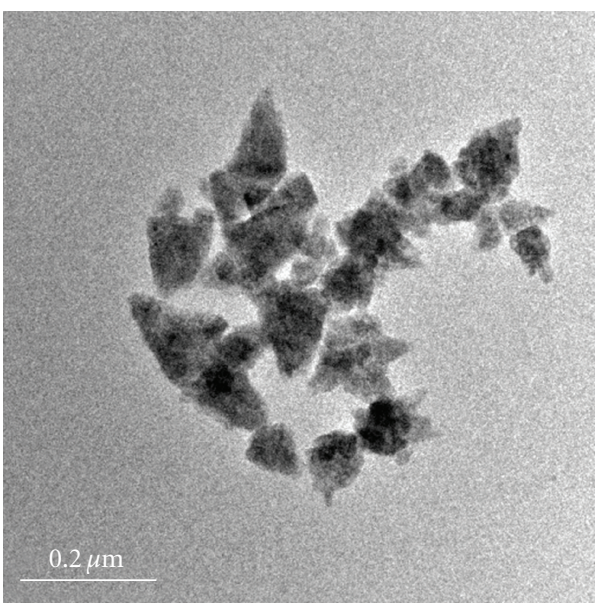

Figure 2: TEM image of ZnO NPs.
TABLE 1: Optimization of the catalyst.

\begin{tabular}{lccc}
\hline \multirow{2}{*}{ S. no. } & \multirow{2}{*}{ Mol \% } & \multicolumn{2}{c}{ ZnO (Vc, yield \%) } \\
& 5 & trace & Nano \\
\hline 1 & 10 & trace & 55 \\
2 & 15 & trace & $89^{\mathrm{a}}, 89^{\mathrm{b}}, 88^{\mathrm{c}}, 87^{\mathrm{d}}$ \\
3 & 20 & trace $^{\mathrm{e}}$ & 90 \\
4 & ${ }^{\mathrm{a}}$ fresh, ${ }^{\mathrm{b}}$ 1st run, ${ }^{\mathrm{c}}$ 2nd run, ${ }^{\mathrm{d}}$ 3rd run, ${ }^{\mathrm{e}} \mathrm{ZnO}$ (bulk) tried up to $30 \mathrm{~mol} \%$.
\end{tabular}

TABle 2: Effect of solvent on $10 \mathrm{~mol} \% \mathrm{ZnO}$ NPs mediated amination of isocoumarins.

\begin{tabular}{lcccc}
\hline \multirow{2}{*}{ Compound } & \multirow{2}{*}{$\mathrm{R}$} & \multirow{2}{*}{ Time in hrs } & \multicolumn{2}{c}{ Yield \% } \\
& & & Toluene & Benzene \\
\hline Va & $\mathrm{H}$ & 12 & 70 & 72 \\
Vb & $\mathrm{CH}_{3}$ & 12 & 75 & 76 \\
Vc & $\mathrm{F}$ & 10 & 89 & 90 \\
Vd & $\mathrm{Cl}$ & 10 & 84 & 85 \\
Ve & $\mathrm{Br}$ & 10 & 80 & 83 \\
Vf & $\mathrm{NO}_{2}$ & 36 & - & - \\
\hline
\end{tabular}

TABLE 3: Comparison of pTSA and ZnO NPs.

\begin{tabular}{|c|c|c|c|c|c|}
\hline \multirow{2}{*}{ Compound } & \multirow{2}{*}{$\mathrm{R}$} & \multirow{2}{*}{$\begin{array}{c}\text { Time in hrs } \\
\text { pTSA }\end{array}$} & \multicolumn{3}{|c|}{ Yield \% } \\
\hline & & & Nano $\mathrm{ZnO}$ & pTSA & Nano $\mathrm{ZnO}$ \\
\hline Va & $\mathrm{H}$ & 32 & 12 & 60 & 70 \\
\hline $\mathrm{Vb}$ & $\mathrm{CH}_{3}$ & 32 & 12 & 62 & 75 \\
\hline Vc & F & 24 & 10 & 70 & 89 \\
\hline Vd & $\mathrm{Cl}$ & 26 & 10 & 65 & 84 \\
\hline Ve & $\mathrm{Br}$ & 26 & 10 & 69 & 80 \\
\hline Vf & $\mathrm{NO}_{2}$ & 36 & 36 & - & - \\
\hline
\end{tabular}

the isocoumarins III $(1 \mathrm{mmol})$ and 1,7-heptadiamine IV $(0.5 \mathrm{mmol})$ in the presence of catalytic amount of pTSA and dry toluene using Dean-stark apparatus (Scheme 2; Table 1). However, the reaction required longer time of 24-32 h for completion and the purity of products was not impressive. 


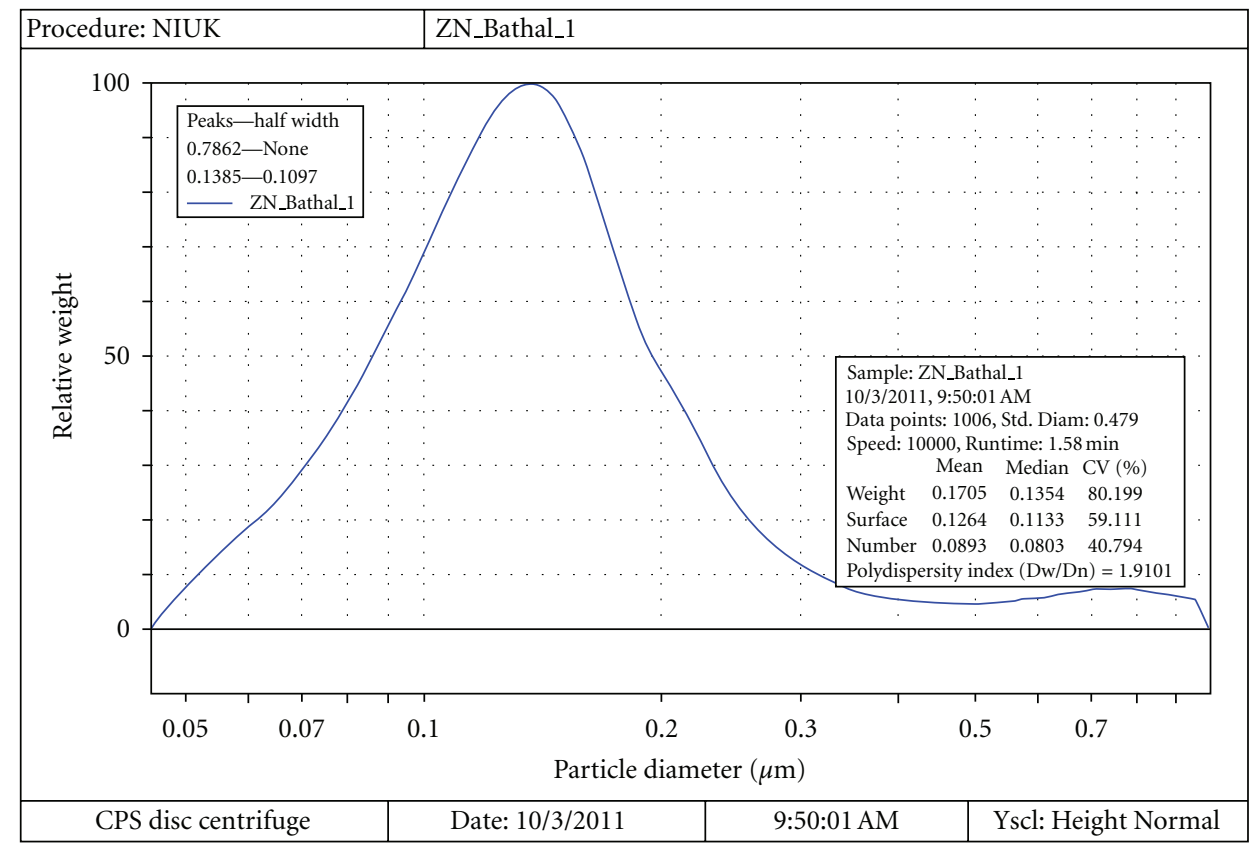

Figure 3: Particle size analyzer.

Full-scale 2236 cts cursor: -0.199 ( 0 cts $)$

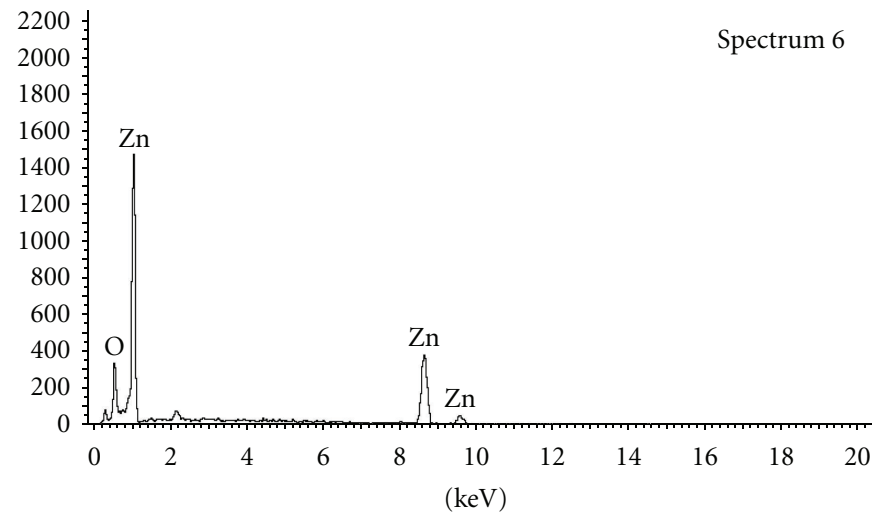

Figure 4: EDX spectrum of ZnO NPs.

The formed products were purified and characterized by various spectral techniques such as FTIR, ${ }^{1} \mathrm{H}$ NMR, ${ }^{13} \mathrm{C}$ NMR, and HRMS techniques.

In the search of reducing the reaction time and to improve the yield and purity of the products, it was evidenced that indium trichloride [24] was an effective catalyst; however, due to their cost and toxicity $[25,26]$, we envisioned the application of an inexpensive and environmentally benign catalysts. The optimization of the reaction was carried out by varying the catalyst, solvent, reactant substituents.

Initially, the $\mathrm{ZnO}$ (bulk) was used as a catalyst for the reaction. In our attempt, in the presence of 5 to $25 \mathrm{~mol}$ $\% \mathrm{ZnO}$ (bulk) catalyst, the reaction continued until $36 \mathrm{~h}$ without formation of the desired product, V. Then, we investigated the presently synthesized $\mathrm{ZnO}$ NPs catalyst in the presence of dry toluene, and it was noticed that $\mathrm{ZnO}$ NPs ( $10 \mathrm{~mol} \%$ ) mediation improved the reaction yield along with reduced time of 10-12 h (Table 1 entry 2 ).

The optimization of the catalyst was done using the reaction between 3-(4-fluorophenyl)-1H-isochromen-1-one (IIIc) and 1,7-heptadiamine (IV) in the presence of ZnO NPs to afford the product Vc in high yield (Table 1). Further, it was noticed that the effect of solvent plays a role towards reaction time and that in benzene solvent the yield and purity was increased with reduced reaction time period (Table 2).

The effect of substituents on the reaction was also investigated, and it was observed that the rate of the reaction (Table 2) was increased in the presence of electron donating substituents (entry b) compared to electron withdrawing substituents (entries c, d, and e); however, in the case of 
TABLE 4: Physical data.

White solid, $\mathrm{mp} 121-123^{\circ} \mathrm{C}, \mathrm{IR} \mathrm{cm}{ }^{-1} 1647(\mathrm{C}=\mathrm{O}), 1336(\mathrm{C}-\mathrm{N}),{ }^{1} \mathrm{H}$ NMR $\left(400 \mathrm{MHz}, \mathrm{CDCl}_{3}\right) \delta 0.96(\mathrm{~m}, 6 \mathrm{H}), 1.46(\mathrm{~m}, 4 \mathrm{H})$, $3.86\left(\mathrm{t}, 4 \mathrm{H}, J=8.0 \mathrm{~Hz}, \mathrm{~N}-\mathrm{CH}_{2}\right), 6.38(\mathrm{~s}, 2 \mathrm{H}), 7.37-7.63(\mathrm{~m}, 16 \mathrm{H}), 8.44(\mathrm{~d}, 2 \mathrm{H}, J=4.0 \mathrm{~Hz}) \mathrm{ppm} .{ }^{13} \mathrm{C} \mathrm{NMR}\left(100 \mathrm{MHz} \mathrm{CDCl}_{3}\right)$

Va $\delta 26.55,28.32,28.61,45.55$ (symmetrical aliphatic carbons), 107.84, 125.34, 125.83, 126.63, 128.01, 128.81, 128.98, 129.14, 132.32, 136.21, 136.39, 143.75, 162.85 (symmetrical carbonyl carbons) ppm, HRMS [EI, M+] calcd for $\mathrm{C}_{37} \mathrm{H}_{34} \mathrm{~N}_{2} \mathrm{O}_{2} \mathrm{~m} / \mathrm{z}$ 538.2620, found 537.8527.

Off white solid, $\mathrm{mp} 110-112^{\circ} \mathrm{C}$, IR cm ${ }^{-1} 1647(\mathrm{C}=\mathrm{O}), 1339(\mathrm{C}-\mathrm{N}),{ }^{1} \mathrm{H}$ NMR $\left(400 \mathrm{MHz}, \mathrm{CDCl}_{3}\right) \delta 0.88(\mathrm{~m}, 6 \mathrm{H}), 1.25(\mathrm{~s}, 6 \mathrm{H})$, $1.45(\mathrm{~m}, 4 \mathrm{H}), 3.85\left(\mathrm{t}, 4 \mathrm{H}, J=4.0 \mathrm{~Hz}, \mathrm{~N}-\mathrm{CH}_{2}\right), 6.35(\mathrm{~s}, 2 \mathrm{H}), 7.26-7.47(\mathrm{~m}, 14 \mathrm{H}), 8.41(\mathrm{~d}, 2 \mathrm{H}, J=8.0 \mathrm{~Hz}) \mathrm{ppm} ;{ }^{13} \mathrm{C} \mathrm{NMR}$

$\mathrm{Vb}$ $\left(100 \mathrm{MHz}, \mathrm{CDCl}_{3}\right) \delta 26.62,28.40,28.70,29.90,45.58$ (symmetrical aliphatic carbons), 107.80, 125.49, 125.83, 126.65, 128.21, $128.57,129.04,129.20,132.31,135.13,136.45,143.79,162.77$ (symmetrical carbonyl carbons) ppm, HRMS [EI, M+] calcd for $\mathrm{C}_{39} \mathrm{H}_{38} \mathrm{~N}_{2} \mathrm{O}_{2} \mathrm{~m} / \mathrm{z}$ 566.2933, found 565.7487 .

White solid, mp $117-119^{\circ} \mathrm{C}$, IR cm ${ }^{-1} 1646(\mathrm{C}=\mathrm{O}), 1336(\mathrm{C}-\mathrm{N}), 694(\mathrm{C}-\mathrm{F}),{ }^{1} \mathrm{H}$ NMR $\left(500 \mathrm{MHz}, \mathrm{CDCl}_{3}\right) \delta 1.02(\mathrm{~m}, 6 \mathrm{H}), 1.48$ $(\mathrm{m}, 4 \mathrm{H}),), 3.88\left(\mathrm{t}, 4 \mathrm{H}, J=7.5 \mathrm{~Hz}, \mathrm{~N}-\mathrm{CH}_{2}\right), 6.37(\mathrm{~s}, 2 \mathrm{H}), 7.28-7.66(\mathrm{~m}, 14 \mathrm{H}), 8.44(\mathrm{~d}, 2 \mathrm{H}, J=8.0 \mathrm{~Hz}) \mathrm{ppm} .{ }^{13} \mathrm{C} \mathrm{NMR}$

Vc $\left(125 \mathrm{MHz}, \mathrm{CDCl}_{3}\right) \delta 26.41,28.39,28.62,45.45$ (symmetrical aliphatic carbons), 107.95, 123.21, 125.35, 125.77, 126.80, $127.99,130.68,131.69,132.33,135.13,136.07,142.37,162.67$ (symmetrical carbonyl carbons) ppm, HRMS [EI, M+] calcd for $\mathrm{C}_{37} \mathrm{H}_{32} \mathrm{~F}_{2} \mathrm{~N}_{2} \mathrm{O}_{2} \mathrm{~m} / \mathrm{z} 574.659$, found 574.5888 .

Pale yellow solid, $\mathrm{mp} 135-138^{\circ} \mathrm{C}, \mathrm{IR} \mathrm{cm}^{-1} 1646(\mathrm{C}=\mathrm{O}), 1337(\mathrm{C}-\mathrm{N}), 687(\mathrm{C}-\mathrm{Cl}),{ }^{1} \mathrm{H}$ NMR $\left(400 \mathrm{MHz}, \mathrm{CDCl}_{3}\right) \delta 1.03(\mathrm{~m}$, $6 \mathrm{H}), 1.45(\mathrm{~m}, 4 \mathrm{H}), 3.85\left(\mathrm{t}, 4 \mathrm{H}, J=7.6 \mathrm{~Hz}, \mathrm{~N}-\mathrm{CH}_{2}\right), 6.35(\mathrm{~s}, 2 \mathrm{H}), 7.26-7.64(\mathrm{~m}, 14 \mathrm{H}), 8.41(\mathrm{~d}, 2 \mathrm{H}, J=0.4 \mathrm{~Hz}) \mathrm{ppm} .{ }^{13} \mathrm{C} \mathrm{NMR}$

Vd $\left(100 \mathrm{MHz}, \mathrm{CDCl}_{3}\right) \delta 26.41,28.37,28.60,45.55$ (symmetrical aliphatic carbons), 108.06, 125.29, 125.77, 126.80, 127.96, $128.72,130.40,132.34,134.61,135.03,136.07,142.31,162.70$ (symmetrical carbonyl carbons) ppm, HRMS [EI, M+] calcd for $\mathrm{C}_{37} \mathrm{H}_{32} \mathrm{Cl}_{2} \mathrm{~N}_{2} \mathrm{O}_{2} \mathrm{~m} / \mathrm{z} 606.1841$, found 606.8743 .

White solid, mp $125-127^{\circ} \mathrm{C}$, IR cm ${ }^{-1} 1677(\mathrm{C}=\mathrm{O}), 1321(\mathrm{C}-\mathrm{N}), 696(\mathrm{C}-\mathrm{Br}),{ }^{1} \mathrm{H} \mathrm{NMR}\left(500 \mathrm{MHz}, \mathrm{CDCl}_{3}\right) \delta 1.02(\mathrm{~m}, 6 \mathrm{H})$, $1.48(\mathrm{~m}, 4 \mathrm{H}), 3.88\left(\mathrm{t}, 4 \mathrm{H}, J=7.5 \mathrm{~Hz}, \mathrm{~N}-\mathrm{CH}_{2}\right), 6.38(\mathrm{~s}, 2 \mathrm{H}), 7.28-7.66(\mathrm{~m}, 14 \mathrm{H}), 8.44(\mathrm{~d}, 2 \mathrm{H}, J=8.0 \mathrm{~Hz}) \mathrm{ppm} .{ }^{13} \mathrm{C} \mathrm{NMR}$

Ve $\left(125 \mathrm{MHz}, \mathrm{CDCl}_{3}\right) \delta 26.41,28.38,28.62,45.46$ (symmetrical aliphatic carbons), 107.98, 123.21, 125.33, 125.78, 126.81, $127.99,130.68,131.69,132.34,135.12,136.07,142.36,162.68$ (symmetrical carbonyl carbons) ppm, HRMS [EI, M+] calcd for $\mathrm{C}_{37} \mathrm{H}_{32} \mathrm{Br}_{2} \mathrm{~N}_{2} \mathrm{O}_{2} \mathrm{~m} / \mathrm{z}$ 696.4702, found 696.3511.

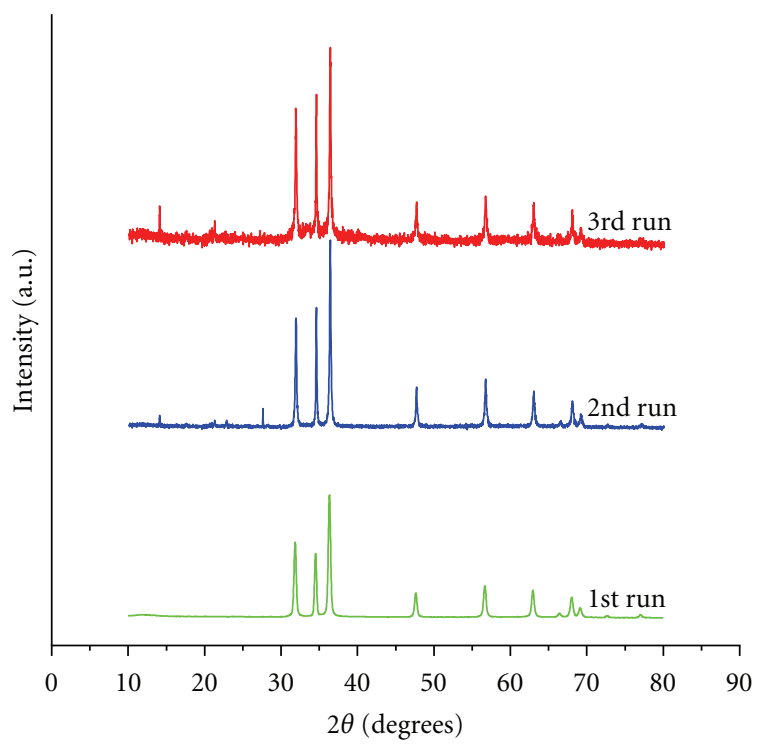

FIGURE 5: XRD spectrum of reutilized ZnO NPs.

nitrosubstitution, there is no progression in the reaction, even after the reaction continued up to 36 hours (entry f).

The reusability of the catalyst was investigated by considering the reaction between IIIc and IV to afford Vc. The catalyst was recovered from the reaction mixture easily by filtration after first run. Then, it was washed with distilled water and ethyl alcohol three times and dried at hot air oven for $1 \mathrm{~h}$. The recovered catalyst was unaltered (Figure 5) and used thrice to obtain the desired product without

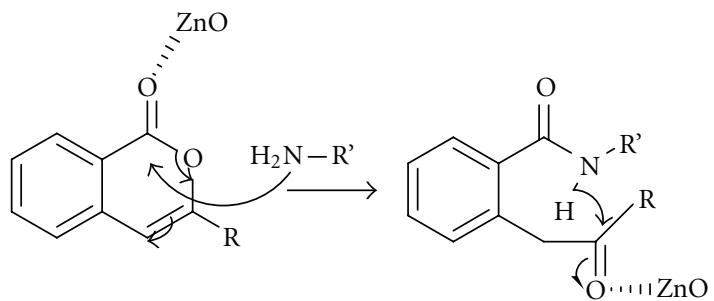

III

$\mathrm{I}_{\mathrm{A}}$<smiles>[R]c1cc2ccccc2c(=O)n1[R]</smiles>

Figure 6: Plausible mechanism for the amination of isocoumarins.

considerable loss of yield 89,88 , and $87 \%$, respectively. It is noteworthy that the yield of the product in the first, second, and third runs was almost the same as that in the fresh catalyst run (Table 1).

A comparison has been made between the pTSA and $\mathrm{ZnO}$ NPs as represented in Table 3. The physical data of bisisoquinolinones are given in Table 4 .

The plausible mechanism involving the role of ZnO NPs in the condensation of isocoumarins and diamine to afford the corresponding isoquinolinones are given as in Figure 6. The mechanism gets initiated through the activation of the carbonyl group by the $\mathrm{ZnO}$ NPs with the subsequent 
nucleophilic attack of the amines to form the corresponding $\mathbf{I}_{\mathbf{A}}$ amide derivatives which then cyclized again with the mediation of ZnO NPs affording the corresponding hydroxyl derivative $\mathbf{I}_{\mathbf{H}}$ which then facilitates the elimination of water to afford the bis-isoquinolinones $\mathbf{V}$, the catalyst regenerated then activate further isocoumarins and the cycle is continued.

3.1. HRMS, FTIR, and NMR Spectra. The HRMS of bisisoquinolinones $\mathbf{V}$ showed a molecular ion peak $\mathrm{M}+$ in the positive mode. The molecular ion peak of Va was observed at $\mathrm{m} / \mathrm{z}=537.8527$, similarly, that of others (Vb-e) were observed at $\mathrm{m} / \mathrm{z} 565.7487,574.5888,606.8743$, and 696.3511, respectively.

In FTIR spectrum, the bis-isoquinolinones (Va-e) inferred the carbonyl frequency at around $1646-1647 \mathrm{~cm}^{-1}$. The bis-isoquinolinones $\mathbf{V}$ are symmetric with respect to the middle carbon of the heptyl group, and hence there are four magnetically equivalent carbons which appeared in the aliphatic region; the corresponding protons resonated at lower chemical shifts. Similarly, the two $\mathrm{CH}$ protons of the isoquinolinone rings appeared as singlet in ${ }^{1} \mathrm{H}$ NMR and the aromatic ring at its 3-position and the other protons of the isoquinolinone ring appeared at higher chemical shifts. The ${ }^{13} \mathrm{C}$ NMR peaks appeared between $\delta 162.70-162.85$ also indicated the symmetrical carbonyl groups of isoquinolinone rings.

\section{Conclusion}

In short, a green, inexpensive, and efficient method for the synthesis of bis-isoquinolinone using $\mathrm{ZnO}$ NPs as a reusable catalyst was established. This new strategy has the several advantages including mild conditions, high yield, efficient, and environmentally benign approach which overcomes the drawbacks of the earlier condensation methods.

\section{Acknowledgments}

The author V. Krishnakumar is grateful to VIT University for their financial assistance as research associateship. The authors also thank VIT University for XRD analysis and providing lab facility. They also acknowledge SAIF, IIT Madras, Chennai for providing NMR and HRMS facility.

\section{References}

[1] E. C. S. Lopes and F. Coelho, "Studies toward the synthesis of Amaryllidaceae alkaloids from Morita-BaylisHillman adducts. A straightforward synthesis of functionalized dihydroisoquinolin-5(6H)-one core," Journal of the Brazilian Chemical Society, vol. 18, no. 7, pp. 1415-1438, 2007.

[2] P. Ray, J. Wright, J. Adam et al., "Fragment-based discovery of 6-substituted isoquinolin-1-amine based ROCK-I inhibitors," Bioorganic and Medicinal Chemistry Letters, vol. 21, no. 1, pp. 97-101, 2011.

[3] A. A. Trabanco, G. Duvey, J. M. Cid et al., "New positive allosteric modulators of the metabotropic glutamate receptor
2 (mGluR2): identification and synthesis of N-propyl-8chloro-6-substituted isoquinolones," Bioorganic and Medicinal Chemistry Letters, vol. 21, no. 3, pp. 971-976, 2011.

[4] J. Roth, F. Madoux, P. Hodder, and W. R. Roush, "Synthesis of small molecule inhibitors of the orphan nuclear receptor steroidogenic factor-1 (NR5A1) based on isoquinolinone scaffolds," Bioorganic and Medicinal Chemistry Letters, vol. 18, no. 8, pp. 2628-2632, 2008.

[5] M. Rudyanto, Y. Tomizawa, H. Morita, and T. Honda, "First total synthesis of cassiarin A, a naturally occurring potent antiplasmodial alkaloid," Organic Letters, vol. 10, no. 10, pp. 1921-1922, 2008.

[6] C. H. Yang, C. C. Tai, and I. W. Sun, "Synthesis of a high-efficiency red phosphorescent emitter for organic lightemitting diodes," Journal of Materials Chemistry, vol. 14, no. 6, pp. 947-950, 2004.

[7] H. H. Huang, S. Y. Chu, P. C. Kao, C. H. Yang, and I. W. Sun, "High efficiency red organic light-emitting diodes using a phosphorescent iridium complex doped into a hole-blocking material," Thin Solid Films, vol. 517, no. 13, pp. 3788-3791, 2009.

[8] R. J. Snow, T. Butz, A. Hammach et al., "Isoquinolinone synthesis by SNAr reaction: a versatile route to imidazo[4,5h] isoquinolin-9-ones," Tetrahedron Letters, vol. 43, no. 42, pp. 7553-7556, 2002.

[9] P. G. Jagtap, E. Baloglu, G. Southan et al., "Facile and convenient syntheses of 6,11-dihydro-5H-indeno[1,2-c] isoquinolin-5-ones and 6,11-dihydro-5H-indolo[3,2-c]isoquinolin-5-one," Organic Letters, vol. 7, no. 9, pp. 1753-1756, 2005.

[10] W. J. Cho, M. J. Park, T. Imanishi, and B. H. Chung, "A novel synthesis of benzo[c]phenanthridine skeleton and biological evaluation of isoquinoline derivatives," Chemical and Pharmaceutical Bulletin, vol. 47, no. 6, pp. 900-902, 1999.

[11] R. P. Korivi and C. H. Cheng, "Protecting-group-free total synthesis of isoquinoline alkaloids by nickel-catalyzed annulation of o-halobenzaldimine with an alkyne as the key step," Chemistry, vol. 16, no. 1, pp. 282-287, 2010.

[12] T. Miura, M. Yamauchi, and M. Murakami, "Synthesis of $1(2 \mathrm{H})$-isoquinolones by the nickel-catalyzed denitrogenative alkyne insertion of 1,2,3-benzotriazin-4(3H)-ones," Organic Letters, vol. 10, no. 14, pp. 3085-3088, 2008.

[13] L. E. Fisher, J. M. Muchowski, and R. D. Clark, "Heteroatomdirected metalation. Lithiation of N-propenylbenzamides and $\mathrm{N}$-propenyl-O-toluamides. Novel routes to ortho-substituted primary benzamide derivatives and $\mathrm{N}$-unsubstituted isoquinolin-1 (2H)-ones," Journal of Organic Chemistry, vol. 57, no. 9, pp. 2700-2705, 1992.

[14] S. E. Davis, A. C. Church, C. L. Griffith, and C. F. Beam, "The preparation of substituted $1(2 \mathrm{H})$-isoquinolinones from dilithiated 2- methyl-N-arylbenzamides, 2-methyl-N(arylmethyl)-benzamides, or 2- methylbenzoic acid, 2,2dimethylhydrazide," Synthetic Communications, vol. 27, no. 17, pp. 2961-2969, 1997.

[15] Y. Kajita, S. Matsubara, and T. Kurahashi, "Nickel-catalyzed decarbonylative addition of phthalimides to alkynes," Journal of the American Chemical Society, vol. 130, no. 19, pp. 60586059, 2008.

[16] N. Guimond, C. Gouliaras, and K. Fagnou, "Rhodium(III)catalyzed isoquinolone synthesis: the $\mathrm{N}-\mathrm{O}$ bond as a handle for C-N bond formation and catalyst turnover," Journal of the American Chemical Society, vol. 132, no. 20, pp. 6908-6909, 2010.

[17] F. Wang, H. Liu, H. Fu, Y. Jiang, and Y. Zhao, "An efficient one-pot copper-catalyzed approach to isoquinolin-1(2H)-one 
derivatives," Organic Letters, vol. 11, no. 11, pp. 2469-2472, 2009.

[18] Z. Zheng and H. Alper, "Palladium-catalyzed carbonylationdecarboxylation of diethyl(2-iodoaryl) malonates with imidoyl chlorides: an efficient route to substituted isoquinolin1(2H)-ones," Organic Letters, vol. 10, no. 21, pp. 4903-4906, 2008.

[19] P. Manivel, F. N. Khan, and V. R. Hatwar, "Synthesis of diversified thioethers, 1-aroylalkylisoquinolin-1-yl thioethers, by electrophilic S-alkylation of 3-phenyl isoquinoline-1 $(2 \mathrm{H})$ thione," Phosphorus, Sulfur and Silicon and the Related Elements, vol. 185, no. 9, pp. 1932-1942, 2010.

[20] P. Manivel, V. R. Hathwar, T. Maiyalagan, V. Krishnakumar, and F. N. Khan, "1-(3,5-Dimethyl-1H-pyrazol-1-yl)-3phenyl-isoquinoline," Acta Crystallographica Section E, vol. 65, no. 8, p. o1798, 2009.

[21] P. D. Burton, E. J. Peterson, T. J. Boyle, and A. K. Datye, "Synthesis of high surface area $\mathrm{ZnO}(0001)$ plates as novel oxide supports for heterogeneous catalysts," Catalysis Letters, vol. 139, no. 1-2, pp. 26-32, 2010.

[22] P. Manivel, A. Sharma, T. Maiyalagan, M. R. Rajeswari, and F. N. Khan, "Synthesis and antiproliferative activity of some $1 \mathrm{H}$-isochromen-1-ones and their thio analogues," Phosphorus, Sulfur and Silicon and the Related Elements, vol. 185, no. 2, pp. 387-393, 2010.

[23] Z. Hu, G. Oskam, and P. C. Searson, "Influence of solvent on the growth of $\mathrm{ZnO}$ nanoparticles," Journal of Colloid and Interface Science, vol. 263, no. 2, pp. 454-460, 2003.

[24] H. N. Harishkumar, V. K. Hulikal, and K. M. Mahadevan, "Aqueous synthesis of N-phenyl/alkyl-2-quinolinone-3carboxylic acids from coumarin-3-carboxylic acids," Synthetic Communications, vol. 40, no. 22, pp. 3281-3289, 2010.

[25] F. P. Castronovo and H. N. Wagner, "Comparative toxicity and pharmacodynamics of ionic indium chloride and hydrated indium oxide," Journal of Nuclear Medicine, vol. 14, no. 9, pp. 677-682, 1973.

[26] T. Nakajima, T. Okada, and I. Kuruma, "Calmodulin antagonistic action of the cerebral circulation improver 6,7dimethoxy-1-(3,4-dimethoxybenzyl)-4-[4-(2-methoxyphenyl)-1-p iperazinyl]methylisoquinoline," Teratogenesis Carcinogenesis and Mutagenesis, vol. 37, no. 6, pp. 674-679, 1987. 


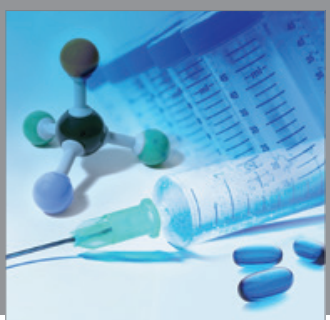

International Journal of

Medicinal Chemistry

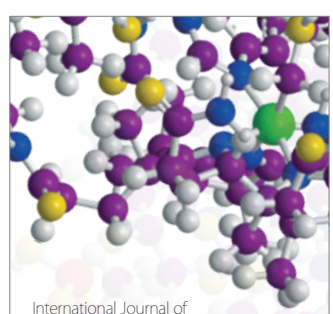

Carbohydrate Chemistry

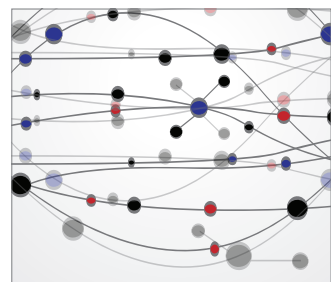

The Scientific World Journal
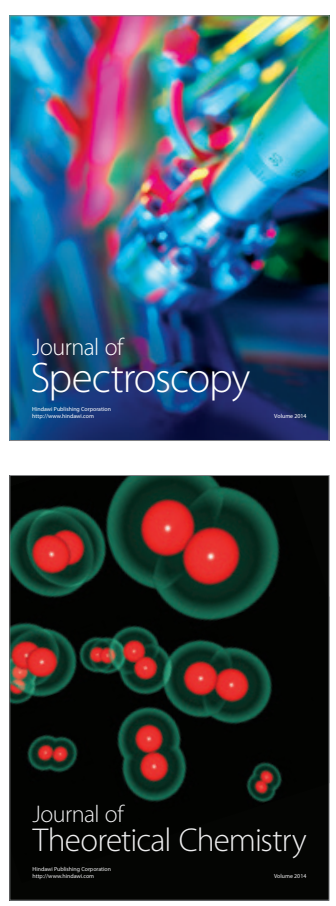
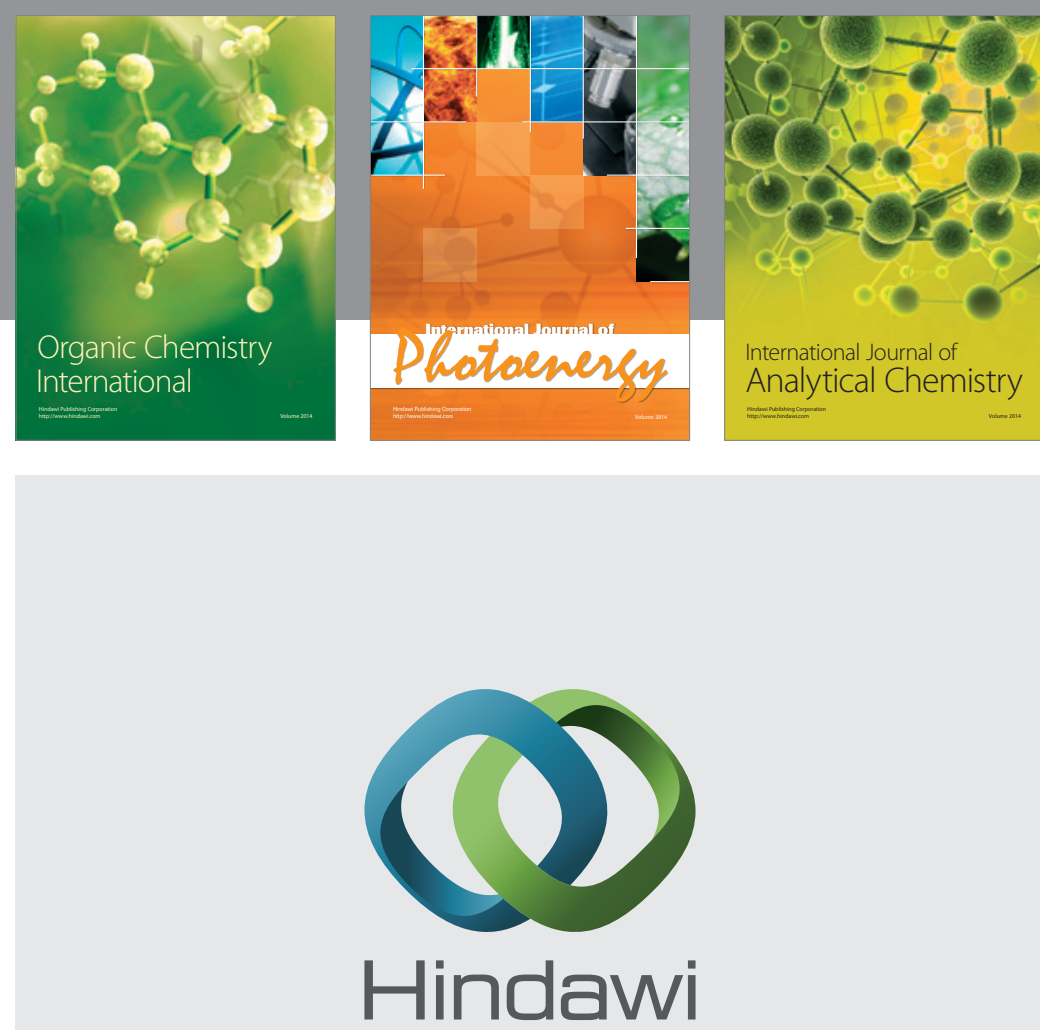

Submit your manuscripts at

http://www.hindawi.com
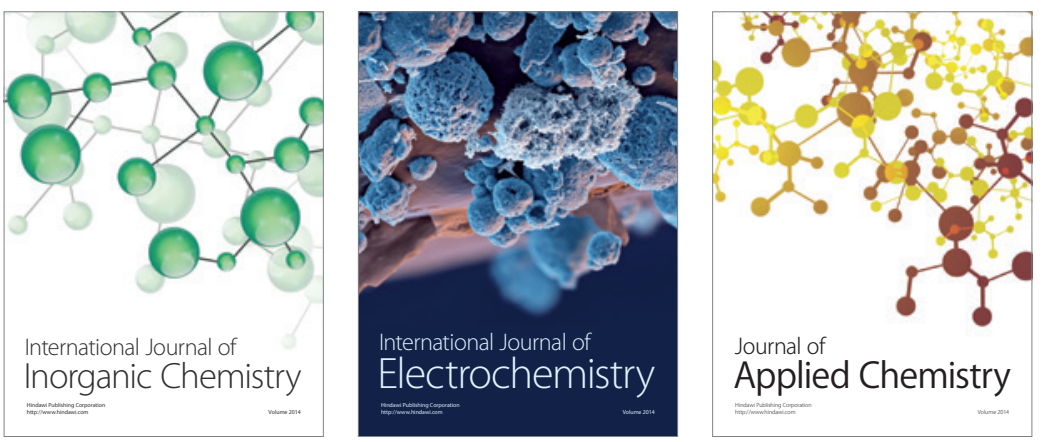

Journal of

Applied Chemistry
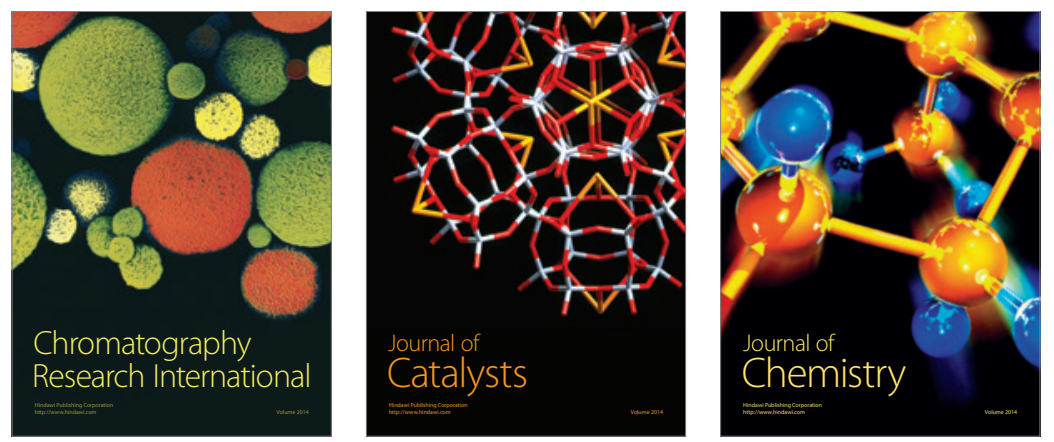
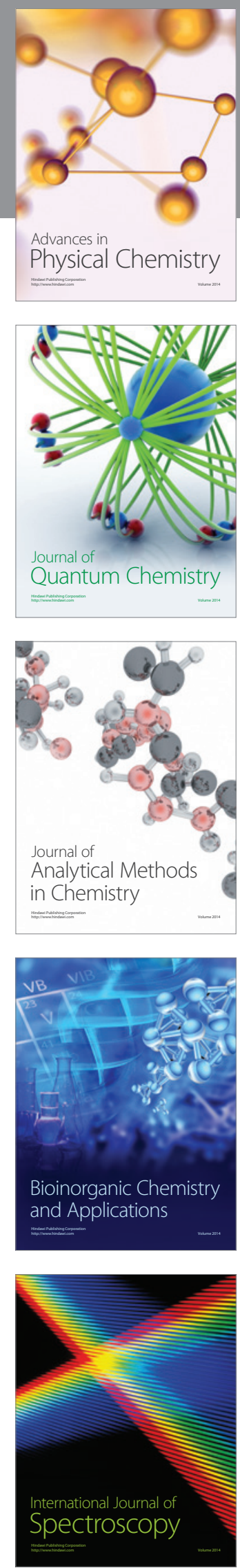